\title{
Outcome of Lower Ureteric Stone Fragmentation by Laser in Comparison with Pneumatic Lithotripsy
}

\author{
SA Anowar Ul Quadir1, Khan Nazrul Islam², Md. Mostafizur Rahman ${ }^{3}$, Md. Shafiqul Alam Chowdhury ${ }^{4}$, \\ SM Mahbub Alam ${ }^{5}$
}

Received: 17 - 07 - 2020

Accepted: 30 - 08 - 2020

Conflicts of interest: None
Keywords: Pneumatic lithotripsy; Laser lithotripsy; Ureteral stone; YAG laser

\begin{abstract}
Background: Several different modalities are available for ureteral stone fragmentation. From them pneumatic and holmium: yttrium-aluminum-garnet (Ho: YAG) lithotripsy have supportive outcomes.

Aims: To see the outcome of lower ureteric stone fragmentation by laser in comparison with pneumatic lithotripsy.

Methods: The prospective clinical study was conducted during the period from July 2012 to June 2014 in Dhaka Medical College Hospital. From the patient admitted in Dhaka medical college hospital a total of 60 patient were selected using purposive sampling methods. Selected patients were numbered chronologically and odd number group as group A (laser lithotripsy) and even number group B (pneumatic lithtripsy). Cystoscopy followed by ureterescopy with the help of guide wire was done and stone fragmentation done by either laser lithotripsy (done in general operation theatre in Dhaka Medical College Hospital) or pneumatic lithotripsy (done in Urology operation theatre in Dhaka Medical College Hospital). Collected data were processed and analyzed using computer software SPSS (statistical package for social science), version-18. Un-pair t-test, chisquare test and Fishers Exact probability test were used to analyze the data. The findings of the study showed age and sex are almost identically distributed in both groups.
\end{abstract}

Results: The mean age of group $A$ and group- $B$ were $35.63 \pm 11.66$ and $38.90 \pm 11.21$ years respectively. A male predominance was observed in both groups with $70 \%$ male in group- $A$ and $53.3 \%$ in group-B. Stone size was also observed identically in both groups. $43 \%$ of stone are larger than $10 \mathrm{~mm}$ in group- $A$ and $47 \%$ stone are larger than $10 \mathrm{~mm}$. None of other baseline variable found very between groups. Immediate stone clearance was much higher in group- $A$ $(96.7 \%)$ then that in group- B (80\%). Although both the groups demonstrated $100 \%$ clearance after 1 month. Immediate complications were higher in group $B$ then those of group- $A$. Ureteral perforation in group $B$ was found $6.7 \%$ as opposed to none in group- $A$. Fever in group $A$ $(6.7 \%)$ was observed to be more than 3 times higher than in group- B (23.3\%). Comparison of complications after 1 and 3 months shows some differences (higher in group-B) but that is not significant. Ureteral stricture developed in 3 patients in group- B compared to nil in group- $A$. More than $90 \%$ of patients of group-A were released from the hospital within 3 days after operation, in contrast about $40 \%$ in group-B left the hospital within 3 days.

Conclusion: So, laser lithotripsy is better option for the management of lower ureteric stone by using semi rigid ureteroscope, in term of stone migration, rate of stone fragmentation and clearance, operation time, hospital stay and complication.

1. Asst. Professor, National Institute of Kidney Diseases and Urology.

2. Asst. Professor, National Institute of Kidney Diseases and Urology.

3. Dr. , Assoc. Professor, Mugda Medical Collage and Hospital, Dhaka

4. Vice Principle, Dhaka Medical Collage.

5. Formar Professor and Head of the Dept. (Urology), Dhaka Medical Collage and Hospital

Correspondences: Dr. S A Anowar Ul Quadir, Asst. Professor, Dept. of Urology, National Institute of Kidney Diseases and Urology, Shere-Bangla Nagar, Dhaka-1207, Bangladesh, E-mail: qadir.uro@gmail.com 


\section{Introduction}

Stone formation in the kidney is one of the oldest and wide spread diseases known to human being. Calculi have been found in the pelvis, presumably in the bladder, of an Egyptian mummy estimated to be 4800 BC. ${ }^{1}$ Reference to stone formation was made in early Sanskrit written in India in $6^{\text {th }}$ century BC. ${ }^{2}$ The history of stone disease implies that many diverse factors might be involved in its causation, heredity, environment, age, sex, urinary infection, metabolic disease changes and dietary excesses or deficiencies ${ }^{1}$.

The prevalence of the urinary tract stone disease is estimated $2 \%-3 \% .{ }^{3}$ Male to female ratio is $3: 1 .{ }^{4}$ Stone formation requires super saturated urine followed by nucleation and crystal formation. Super saturation depends on urinary $\mathrm{pH}$, ionic strength, solid concentration and complication. The role of solute concentration is clear. As ion concentration increases, their activity product reaches a specific point termed "solubility product" (Ksp). Concentration above this point is capable of initiating crystal growth. Super saturation level beyond this level is unstable and spontaneous nucleation may occur. ${ }^{5}$

Other factors play major roles in development of urinary calculi, including complication. So causes of stone formation may be divided into idiopathic, metabolic, and non-metabolic. Non metabolic causes include obstruction, infection, abnormal anatomy etc. Stone disease is also common in Bangladesh, more common in northern part of the country. ${ }^{2}$ In the management of this problem, Past 20 years had witnessed revolutionary changes in this field. Treatment of stone disease moved dramatically from an open operative procedure to endoscopic, minimally invasive methods and non-invasive methods. ${ }^{6}$

Ureteral stone size less than $5 \mathrm{~mm}$ usually pass spontaneously. ${ }^{7}$ On the other hand stone more than $8 \mathrm{~mm}$ size usually not passes spontaneously. ${ }^{8}$

Treatment of ureteral stone depends on stone size composition, position and degree of obstruction, pain, presence of infection single kidney and abnormal ureteral anatomy. ${ }^{3}$ Surgical treatment option for ureteric stone includes Extra corporeal shock wave lithotripsy, ureteroscopy with lithotripsy have greatly improved the treatment of ureteral stone. ${ }^{3}$ Success rates vary, and appear to be dependent upon device amongst other factors. Ureteroscopy is a common procedure done in Bangladesh, and most of the urologist use pneumatic lithotripsy. Laser lithotripsy is a new procedure in our country. Holmium:YAG laser is being used for different urological procedure in only few center in our country.

The Holmium laser, in particular, provides a very powerful yet safe lithotripsy mechanism. ${ }^{9}$ As commented by Winfield (1996), the intrinsic property of the Holmium laser had provided unsurpassed stone fragmentation including calcium oxalate monohydrate and cysteine stones which could be difficult even for the pulsed dye laser. These changes allow for rapid, safe and in most cases economic way of stone removal. ${ }^{10}$ This is reflected by a number of recent reports of the highly successful Holmium laser lithotripsy. ${ }^{11,12,13}$ It became clear that ureteroscopic lithotripsy should no longer be restricted to the distal ureter, as was the case in the late 70s when the technique was first introduced.

Laser lithotripsy is better option for the management of lower ureteric stone by using semi rigid ureteroscope, in term of stone migration, rate of stone fragmentation and clearance, operation time, hospital stay and complication also. So, comparison of the outcome of pneumatic lithotripsy and laser lithotripsy will guide us for most appropriate procedure for treatment of lower ureteric stone It has been shown that Holmium: YAG lithotripsy is better among other energy source in terms of safety and efficacy.

To my knowledge, no such study has been done in our country. Hence, this study has been designed to comparison of the efficacy and safety of pneumatic and laser lithotripsy for the management of lower ureteric stone.

\section{Methods:}

The study was a prospective study was conducted in the Department of Urology, Dhaka Medical College Hospital Dhaka from July 2012 to June 2014. Sixty patients who attended in the out patients department of urology, Dhaka Medical College Hospital, Dhaka with lower ureteric stone: those who are fulfill the inclusion and exclusion criteria were included for the study sample.

Purposive sampling methods were followed as per inclusion and exclusion criteria. After admission patients were again studied clinically and 60 patients, age ranging from 15-70 years were selected for this study as per selection criteria Incidence of ureteric stone is less in children and instruments for child is not available in our institute. On the other hand comorbidity in elderly people is much more higher and 
for these reasons, these group of patients are not included in our study. The cases were numbered chronologically and odd number grouped as Group A for laser lithotripsy and even number as Group B for pneumatic lithotripsy.

\section{Selection criteria:}

\section{Inclusion criteria:}

1. Patient with lower ureteric stone.

2. Patient between age ranges $15-70$ years.

3. Consent from patient about treatment.

\section{Exclusion criteria:}

1. Stone present in upper part of the ureter.

2. Impacted Stone.

3. Patient in age below 15yr and above $70 \mathrm{yr}$.

4. Patient with abnormal ureteral anatomy (may interfere selective operative procedure.)

5. Pregnancy with ureteric stone.

6. Stone with documented urinary infection

7. Radiolucent stone

8. Renal failure

9. Solitary functioning kidney

10. Patients with co-morbidity like Diabetic, HTN, CVD.

\section{Procedure:}

Informed consent was taken from all patients. A detail data sheet was completed and this included particulars of the patient history, results of physical examinations and relevant baseline investigations Urinalysis (R/ $\mathrm{E}, \mathrm{M} / \mathrm{E}$ and $\mathrm{C} / \mathrm{S}$ ) was advised.

Transabdominal USG was done by the sonologist of Radiology Department, DMCH to detect any hydronephrotic change or any other pathology.

IVU was done to see the size and location of stone, renal function any hydronephrotic changes and any abnormal anatomy. Following General or spinal anesthesia, all patient placed in lithotomy position. In the present study ureteroscopy followed by pneumatic or laser lithotripsy done. Both the procedure are similar in initial part.

Cystoscopy was done for identification of ureteric orifice. Then guide wire was passed within ureteric orifice under visual and fluoroscopic monitoring.

Then Ureteroscope is advanced commonly next to the guide wire. At time a tortuous portion of ureter is encountered, posing a challenge for the passage of the scope. In such cases, a second guide wire may be helpful.

Patient released within 3 days of operation. During operation procedure, all patient were followed properly for all outcome variables (Stone clearance, Ureteral injury, haematuria, Ureteral perforation.).

Stone clearance was checked by ureteroscopy and fluoroscopy at the end of procedure. Any ureteral injury, bleeding, ureteral perforation were immediately noticed and managed accordingly.

Each of the patients was followed up at one month $\left(1^{\text {st }}\right.$ visit) and 3 months ( $2^{\text {nd }}$ visit). All the cases were follow up after 1 month (1st visit) of ureteroscopy (pneumatic or laser lithotripsy) with history, urine examination (R/ $\mathrm{E}, \mathrm{M} / \mathrm{E}$ and $\mathrm{C} / \mathrm{S}$ ) to detect presence of any urinary tract infection, plain $\mathrm{x}$-ray KUB region to see stone clearance. After 3 month (2nd visit), each patient was evaluated by history, Urine examination (R/E, M/E and $C / S$ ) to detect presence of any urinary tract infection, IVU to exclude late complications like ureteric stenosis and stricture. Improvement was assessed on the changes from base line symptoms and findings from investigations.

\section{Ethical issue:}

Ethical clearance for this study will be taken from the Ethical Review Committee of Department of Urology, Dhaka Medical College Hospital Dhaka. The participants were explained the purpose of the study and the importance of such study. The study was conducted with signed informed consent of all the participants with the right to withdraw himself/herself from the study at any time during the study period. Interest of the patient was given highest priority and confidentiality was maintained with safe guard of the right and health of the participants.

\section{Results}

Table-1: Comparison of age between groups.

\begin{tabular}{lccr}
\hline Age (yrs) & \multicolumn{2}{c}{ Group } & p-value \\
\cline { 2 - 3 } & $\begin{array}{c}\text { Group-A } \\
(\mathrm{n}=30)\end{array}$ & $\begin{array}{c}\text { Group-B } \\
(\mathrm{n}=30)\end{array}$ & \\
\hline $15-19$ & $2(6.7)$ & $1(3.3)$ & \\
$20-29$ & $9(30.0)$ & $7(23.3)$ & \\
$30-39$ & $5(16.7)$ & $7(23.3)$ & 0.273 \\
$40-49$ & $9(30.0)$ & $8(26.7)$ & \\
$\geq 50$ (up to 70) & $5(16.7)$ & $7(23.3)$ & \\
Mean \pm SD & $35.63 \pm 11.66$ & $38.90 \pm 11.21$ & \\
\hline
\end{tabular}


Table-1 demonstrates that highest frequency of ureteral stone was observed in age category $40-49$ years $(30.0 \%$ in Group-A and $26.7 \%$ in Group-B) and the least frequency in between 15 - 19 years $(6.7 \%$ in Group-A and $3.3 \%$ in Group-B). The lowest and highest ages in Group-A were 15 and 70 years respectively and those in Group-B were 15 and 70 years respectively.

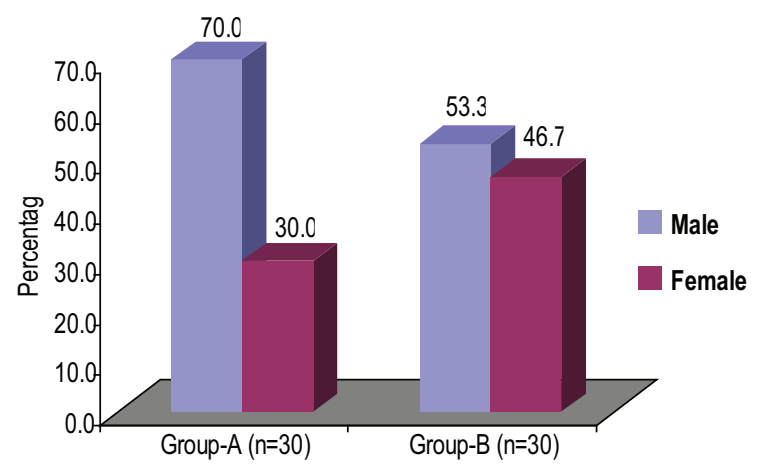

Fig.-1: Sex distribution of the patients in two groups.

Over half (70.0\%) of Group-A and 53.3\% of Group-B were males.

Table-II : Comparison of pertinent baseline variables between groups.

\begin{tabular}{lccc}
\hline $\begin{array}{l}\text { Baseline } \\
\text { variables }\end{array}$ & $\begin{array}{c}\text { Group-A } \\
(\mathrm{n}=30)\end{array}$ & $\begin{array}{c}\text { Group-B } \\
(\mathrm{n}=30)\end{array}$ & $\begin{array}{c}\mathrm{p} \text { - } \\
\text { values }\end{array}$ \\
\hline Stone impaction\# $^{\#}$ & $6(20 \%)$ & $9(30 \%)$ & 0.371 \\
$\begin{array}{l}\text { Stone size \#\# } \\
\text { (Mean } \pm \text { SD) }\end{array}$ & $10.83 \pm 2.52$ & $10.30 \pm 2.04$ & 0.374 \\
Associated UTI & $10(33.3 \%)$ & $1(3.3 \%)$ & 0.002 \\
$\begin{array}{l}\text { IVU excretion } \\
\text { delayed }\end{array}$ & $18(60 \%)$ & $8(26.7 \%)$ & 0.009 \\
IVU (P-C) system $_{\text {dilated }}^{\#}$ & $16(53.3 \%)$ & $17(56.7 \%)$ & 0.795 \\
\hline
\end{tabular}

\# value reached from Chi-square test

\#\# p value reached from Unpaired student t-test

Table-II demonstrates the comparison of baseline variables that might be influence on the outcome of intervention. The variables chosen were stone impaction, stone size, associated UTI, IVU excretion and IVU (P-C) system.

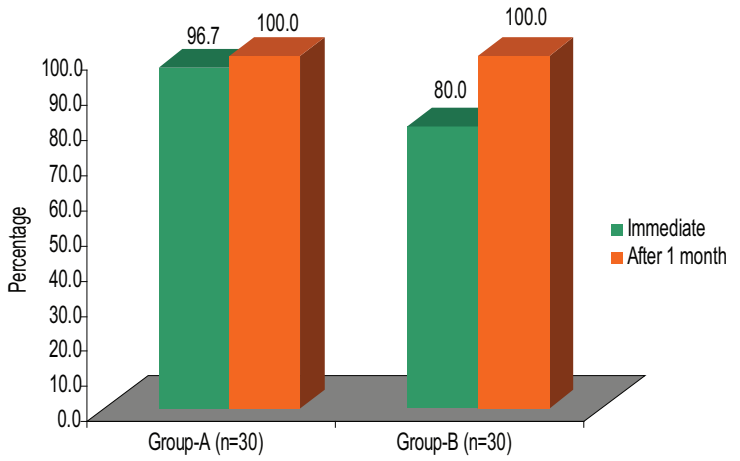

Fig.-2: Comparison of stone clearance

Figure shows that immediate stone clearance was much higher in Group-A (96.7\%) than that in Group-B $(80 \%)$, although both the groups demonstrated $100 \%$ clearance after 1 month.

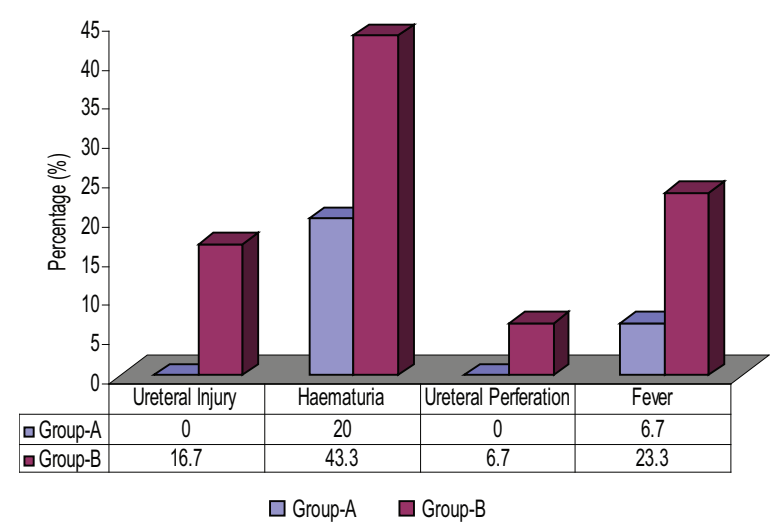

Fig.-3: Comparison of immediate complications

Out of 30 cases, $5(16.7 \%)$ cases had ureteral injury in group-B compared to none in Group-A. Haematuria observed in $6(20 \%)$ cases of group-A compared to $13(43.3 \%)$ cases in group-B. 2(6.7\%) cases had ureteral perforation in group-b compared to none in Group-A. Fever observed in 2(6.7\%) cases of group-A compared to $11(23.3 \%)$ cases in group-B.

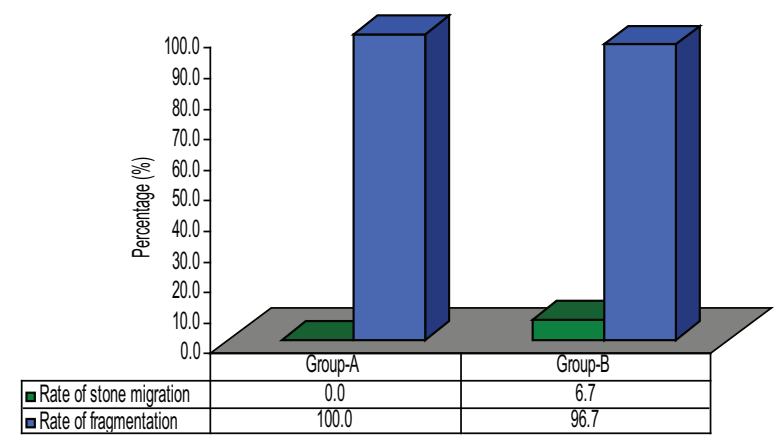

Fig.-4: Rate of stone migration and fragmentation 
Figure- 4 demonstrate the rate of stone migration in Group B (pneumatic lithotripsy) 6.7\% and none in Group A (Laser lithotripsy). Stone fragmentation rate in Group A $100.0 \%$ and $96.7 \%$ in Group B.

Table-III: Comparison of complications after 1 month between groups.

\begin{tabular}{lll}
\hline Complication & \multicolumn{2}{c}{ Group } \\
\cline { 2 - 3 } after 1 month & $\begin{array}{c}\text { Group-A } \\
(\mathrm{n}=30)\end{array}$ & $\begin{array}{c}\text { Group-B } \\
(\mathrm{n}=30)\end{array}$ \\
\hline Pain in the loin & $1(3.3 \%)$ & $3(10 \%)$ \\
\hline
\end{tabular}

All the cases were evaluated after 1 month ( $\left(1^{\text {st }}\right.$ visit $)$ of ureteroscopy with pneumatic or laser lithotripsy. All patients were followed up with history, urine examination (R/E and $C / S)$ to detect presence of any urinary tract infection, plane $\mathrm{X}$-ray KUB region to see stone clearance. Table demonstrates that $1(3.3 \%)$ patients in Group-A,3(10.0\%) patient in Group-B suffered from pain, while none of the patients of either Group-A and Group-B developed infection.

Table-IV : Comparison of complications after 3 months between groups.

\begin{tabular}{lcc}
\hline Complication & \multicolumn{2}{c}{ Group } \\
\cline { 2 - 3 } after 3 months & $\begin{array}{c}\text { Group-A } \\
(\mathrm{n}=30)\end{array}$ & $\begin{array}{c}\text { Group-B } \\
(\mathrm{n}=30)\end{array}$ \\
\hline Ureteral Stricture & 0.0 & $3(10.0 \%)$ \\
\hline
\end{tabular}

Table-4shows that 3(10\%) patients of Group-B developed ureteral stricture, where as none of GroupA developed the same. While none of the patients of either Group-A or Group-B developed infection. After 3 month ( $2^{\text {nd }}$ visit), each patient was evaluated by history, urine examination (R/E, M/E and C/S) to detect presence of any urinary tract infection. IVU was done in 2nd visit to see any ureteral stricture.

Table-5: Comparison of total outcome between groups

\begin{tabular}{|c|c|c|c|}
\hline \multirow[t]{2}{*}{ Baseline variables } & \multicolumn{2}{|c|}{ Group } & \multirow{2}{*}{$\begin{array}{c}\text { p- } \\
\text { values }\end{array}$} \\
\hline & $\begin{array}{l}\text { Group-A } \\
(\mathrm{n}=30)\end{array}$ & $\begin{array}{l}\text { Group-B } \\
(\mathrm{n}=30)\end{array}$ & \\
\hline Stone clearance ${ }^{\#}$ & $29(96.7 \%)$ & $24(80 \%)$ & 0.04 \\
\hline Complication rate $^{\#}$ & $4(13.33 \%)$ & $11(36.66 \%)$ & 0.03 \\
\hline $\begin{array}{l}\text { Mean operation } \\
\text { time (minutes) \#\# }\end{array}$ & \multicolumn{3}{|c|}{$42.17 \pm 8.9768 .33 \pm 11.77<0.001$} \\
\hline $\begin{array}{l}\text { Mean hospital stay } \\
\text { (days) \#\# }\end{array}$ & $2.37 \pm 0.72$ & $4.27 \pm 1.39$ & $<0.001$ \\
\hline
\end{tabular}

\# value reached from Chi-square test

\#\#p value reached from Unpaired student t-test
Table- 5 compares the outcome of the two groups. The outcome variables were stone clearance, complication rate, operation time and hospitals stay. Stone clearance was significantly lower in Group-B 24(80.0\%) than that in Group-A 29(96.7\%). Likewise the complication rate was much higher in the former group B (36.66\%) than that in the latter group A (13.33\%). The mean operation time and mean hospital stay were also much higher in the former group-B than those in the latter group-A suggesting that laser lithotripsy is the better intervention choice than pneumatic lithotripsy for clearance of lower ureteral stone.

\section{Discussion}

Comparison of patient's baseline variables also had done, which might have influence of the outcome of intervention. The variable chosen was stone impaction, stone size, associated urinary tract infection, renal function and condition of the pelvicalyceal system. None of this variable was found to vary between two groups. So, it is obviously seen that both group are almost identical with the consideration age, sex, stone impaction, stone size, associated urinary tract infection, renal function and condition of the pelvicalyceal. So, it is likely to give us more perfect idea of safety and efficacy of intervention (laser lithotripsy or pneumatic lithotripsy) for the management of the lower ureteric stone.

Post operative variable, stone clearance observed in the present study. Out of 30 cases in Group-A shows immediate stone clearance in $29(96.7 \%)$ cases, whereas Group-B shows immediate stone clearance in $24(80.0 \%)$ cases, which is lower. Though both groups demonstrated $100 \%$ clearance after one month. In a study in China, 285 patients underwent endoscopic removal of ureteric stone with either pneumatic lithotripsy (145 patients) or by laser lithotripsy (140 patients). In one single session, the overall successful stone fragmentation rate of laser lithotripsy was higher than that of pneumatic lithotripsy $(95.7 \%$ vs. $69.7 \%$; $\mathrm{P}<0.01) .{ }^{14}$

Ureteroscopic holmium: YAG laser lithotripsy was used in 168 patients of ureteral calculi (mostly lower ureteric stone 108). The stone free rate was $94 \%(102 /$ $108)$ of lower ureteric stone. The complication rate was 5\% (8 cases). They concluded ureteroscopic Holmium: YAG laser lithotripsy is a highly effective and safe treatment modalities. ${ }^{15}$ Larizgoitia $^{16}$ systematically reviewed the current evidence on the use of Holmium: YAG laser in different area of urology. They treated 160 patients of urinary stone, among them Holmium: 
YAG laser causes $97 \%$ clearance, on the other hand electrohydrolic lithotripsy causes $65 \%$ clearance.

Forty seven (47) ureteroscopic laser lithotripsy were performed in 44 patients (three bilateral stones), out of them 37 patients had stone in the lower ureter. The success rate was $91 \% \cdot{ }^{17}$ All these study is shown that Group-A is higher comparable then Group-B, in case of outcome in form of immediate stone clearance. Some of the immediate complication found in study considerably higher in Group-B then those of GroupA. Ureteral injury in Group-B was $16.7 \%$ compared to zero percent in Group-A. Out of 30 cases 5 cases had ureteral injury in Group-B compared to nil in GroupA. In the present study, haematuria observed in 6 cases of group-A compared to 13 cases in Group-B. Haematuria in Group-A (20.0\%) was more than double then that in Group-B (43.7\%). 2 cases had ureterat perforation in Group-B compared to nil in Group A. Ureteral perforation in Group-B was found 6.7\% compared to zero percent in Group-A. Fever is also observed 3 times more in Group-A (6.7\%) then GroupB $(23.3 \%)$. The rate of stone migration in Group B (pneumatic lithotripsy) $6.7 \%$ and none in Group A (Laser lithotripsy). Stone fragmentation rate in Group A $100.0 \%$ and $96.7 \%$ in Group B. Li XC et al. ${ }^{18}$, in a study showed 3 perforation occurred in pneumatic lithotripsy group $(n=201)$, compare to nil in laser lithotripsy group $(n=214)$.In a study in China, 285 patients underwent endoscopic removal of ureteric stone with either pneumatic lithotripsy (145 patients) or by laser lithotripsy (140 patients), where shown 5 perforations in-group where pneumatic lithotripsy was done $(n=145)$ compare to none in laser lithotripsy group $(n=140)$ and the average time to stone-free status was shorter for laser lithotripsy then for pneumatic lithotripsy (18 days VS 31 days, $\mathrm{p}<0.001) .{ }^{14}$

Comparison of complication after one month and three months shows some complication in Group-B (ureteral stricture in 3 patients) compare to nil in Group-A. However difference between complications is not significant $(p=0.119)$. Duration of hospital stay was considered in this study. Mean hospital stay was 2.37 days in group-A and mean hospital stay was 4.27 days in Group-B. More than 90\% of patients of Group-A were released from the hospital within 3 days after operation. In contrast only $40 \%$ of the patients in Group-B left hospital within 3 days. Longer hospital stay in Group-B occurred because more complication. In a study shows that average post operative hospital stay $2.5 \pm 1.7$ days in case of pneumatic lithotripsy and $1.0 \pm .05$ in case of laser lithotripsy, which is almost comparable to this stud. ${ }^{19}$

As outcome is considered it seen that both study group experienced a favorable outcome. So, laser lithotripsy is better option for the management of lower ureteric stone by using semi rigid ureteroscope, in term of stone migration, rate of stone fragmentation and clearance, operation time, hospital stay and complication.

\section{Conclusion}

Laser lithotripsy is better option for the management of lower ureteric stone by using semi rigid ureteroscope, in term of stone migration, rate of stone fragmentation and clearance, operation time, hospital stay and complication also. So, urologist of our country may use laser lithotripsy as energy source for lower ureteral stone management.

\section{References:}

1. Darch ,W. Urolithiasis: Etiology, diagnosis and medical management; Campbell Urology, $8^{\text {th }}$ edi. edt. by PC Walsh, WB Saundus. 1996; 2085-2086.

2. Nadeem M, Ather MH, Jamshaid A, Zaigham S, Mirza R, Salam B. Rationale use of unenhanced multi-detector CT (CT KUB) in evaluation of suspected renal colic. International Journal of Surgery. 2012 Jan 1;10(10):634-7.

3. Uribarri, J., Oh, M.S. and Carroll, H.J., 1989. The first kidney stone. Annals of internal medicine, 111(12), pp.1006-1009.

4. Lingeman, JE. Lifhitz, DA. Evan, AP. Walsh, PC, editor- in chief, Campbell Urology, Philadelphia, W.B. Surgical management of Urinary Lithiasis. Saunders 2002; 337-338.

5. Marshall, LS. Urinary stone disease; Smith's General Urology. $16^{\text {th }}$ Edn. edt. by Emil, A. Tanho Jack, W. McAninch ,MC. Graw Hill, 2000; 256257.

6. Lingeman, JE. Lifhitz, DA. Evan, AP. Surgical management of Urinary Lithiasis. Edt. by Walsh, PC, Campbell Urology, Philadelphia, W.B. Saunders, 2002; 3380-3381.

7. Kinder RB, Osborn DE, Flynn JT, Smart JG. Ureteroscopy and Ureteric Calculic how Useful? British journal of urology. 1987 Dec;60(6):506-8.

8. Ueno A, Kawamura T, Ogawa A, Takayasu H. Relation of spontaneous passage of ureteral calculi to size. Urology. 1977 Dec 1;10(6):544-6. 
9. Sayer J, Johnson DE, Price RE, Cromeens DM. Ureteral lithotripsy with the holmium: YAG laser. Journal of clinical laser medicine \& surgery. 1993 Apr;11(2):61-5.

10. Preminger GM. Technique versus technology: what is the most appropriate method for the removal of ureteral calculi. The Journal of urology. 1994 Jul;152(1):66-67.

11. Erhard MJ, Bagley DH. Urologic applications of the holmium laser: preliminary experience. Journal of endourology. 1995 Oct;9(5):383-6.

12. Matsuoka K, Iida S, Nakanami M, Koga H, Shimada A, Mihara T, Noda S. Holmium: yttriumaluminum-garnet laser for endoscopic lithotripsy. Urology. 1995 Jun 1;45(6):947-52.

13. Grasso M. Experience with the holmium laser as an endoscopic lithotrite. Urology. 1996Aug 1; 48(2):199-206.

14. Sun Y, Wang L, Liao G, Xu C, Gao X, Yang Q, Qian S. Pneumatic lithotripsy versus laser lithotripsy in the endoscopic treatment of ureteral calculi. Journal of endourology. $2001 \mathrm{Aug}$ 1;15(6):587-90.

15. Pang ZL, Xiao CG, Zeng PQ, Lu GC, Zhang QJ. Ureteroscopic holmium: YAG laser lithotripsy for managing urinary tract calculi. Zhonghuawaike za zhi [Chinese journal of surgery]. 2004 Jan;42(2):92-3.

16. Larizgoitia I, Pons JM. A systematic review of the clinical efficacy and effectiveness of the holmium: YAG laser in urology. InDatabase of Abstracts of Reviews of Effects (DARE): Quality-assessed Reviews [Internet] 1999. Centre for Reviews and Dissemination (UK).

17. Yiu MK, Liu PL, Yiu TF, Chan AY. Clinical experience with holmium: YAG laser lithotripsy of ureteral calculi. Lasers in Surgery and Medicine: The Official Journal of the American Society for Laser Medicine and Surgery. 1996;19(1):103-6.

18. Li XC, Liu Y, Yang JG, Zhang DH. Comparative study of pneumatic lithotripsy and holmium laser lithotripsy for ureteral stones. Zhong nan da xuexue bao. Yi xue ban= Journal of Central South University. Medical sciences. 2005 Oct;30(5): 601-3.

19. Jeon SS, Hyun JH, Lee KS. A comparison of holmium: YAG laser with Lithoclast lithotripsy in ureteral calculi fragmentation. International journal of urology. 2005 Jun;12(6):544-7. 